\title{
Comparison of Fetal Main Pulmonary Artery Doppler Wave Forms between Normally Grown and Growth Restricted Fetuses: A Case-Control Study
} \author{
Shideh Ariana ${ }^{4,5}$ \\ ${ }^{1}$ Department of Obstetrics and Gynecology, Arak University of Medical Sciences, Arak, Iran \\ ${ }^{2}$ Department of Obstetrics and Gynecology, Tehran University of Medical Sciences, Tehran, Iran \\ ${ }^{3}$ Division of Perinatology, Shariati Hospital, Tehran, Iran \\ ${ }^{4}$ Department of Obstetrics and Gynecology, Shahid Beheshti University of Medical Sciences, Tehran, Iran \\ ${ }^{5}$ Division of Perinatology, Imam Hossein Hospital, Tehran, Iran
}

Maryam Maktabi ${ }^{* 1}$, Zahra laleh Eslamian ${ }^{2,3}$, Vajiheh Marsoosi ${ }^{2,3}$, Ashraf Jamal ${ }^{2,3}$, Mahsa Naemi ${ }^{2,3}$, Maryam Nourzadeh ${ }^{2,3}$ and $^{2}$

*Corresponding author: Maryam Maktabi, Department of Obstetrics and Gynecology, Arak University of Medical Sciences, Arak, Iran; Email: dr.maryam.maktabi@gmail.com

Received: June 12, 2020; Accepted: June 19, 2020; Published: June 30, 2020

\begin{abstract}
Objective: In this study we aimed to compare the fetal main pulmonary artery (MPA) Doppler wave forms between normally grown and growth restricted fetuses.

Method: In April 2019-March 2020, a single operator, who was unaware of the subsequent analysis, performed prospectively the MPA Doppler measurements including MPA-PI (pulsatility index) and MPA-PSV (peak systolic velocity). The data were then analyzed by SPSS version 21 .

Results: A total of 120 women with singleton pregnancies - 60 normally grown fetuses as controls and 60 growth restricted fetuses as cases-participated in the study. We categorized the fetuses into five gestational age periods: 26-29, 30-32, 33-34, 35-37, and 38-40 weeks.

In all five time intervals the mean of MPA-PI was significantly higher in cases than controls $(\mathrm{P}<0.001)$. The mean of MPA-PI in cases was increasing with gestational age, while in the control group it was decreasing. Also, in all time intervals, the mean of MPA-PSV was significantly higher in the control group $(\mathrm{P}<0.001)$. The mean of MPA-PSV in cases was decreasing by advancing the gestational age, while in the control group it was increasing. In the case group, per one-week increase in gestational age, MPA-PI increased as $16 \%(\mathrm{p}<0.001)$, while MPA-PSV significantly decreased $(\mathrm{p}<0.001)$.
\end{abstract}

Conclusion: According to the results, there are noticeable changes in the right ventricular outflow tract of the fetal heart in the growth restricted fetuses. In comparison with normal fetuses, the fetal MPA-PI increases and the MPA-PSV decreases significantly in growth restricted fetuses.

Keywords: Doppler ultrasound, MPA-PI, MPA-PSV, Growth restriction

\section{Introduction}

Fetal growth restriction (FGR) is associated with several changes at the level of the fetal heart involving preload, after load, ventricular compliance, and myocardial contractility. An increase in after load is seen at the right ventricle owing to increased placental impedance [1]. A decrease in after load is noted at the level of the left ventricle owing to decreased cerebral impedance associated with the brain sparing reflex [1]. Evidence of reduced myocardial contractility in the presence of severe FGR has also been reported. Ventricular ejection force, an index of ventricular systolic function that is independent of preload and after load, is decreased at the level of the right and the left ventricles in FGR [2].

Longitudinal data on the hemodynamic sequence of the natural history of FGR show that the umbilical artery and middle cerebral artery are the first variables to become abnormal [3]. These arterial Doppler abnormalities are followed by abnormalities in the right cardiac diastolic indices, followed by the right cardiac systolic indices, and finally, by both left diastolic and systolic cardiac indices [3]. Several of the Doppler changes seen in association with FGR in the peripheral circulation are directly related to the adaptation of the fetal heart [4].

Normal pregnancy is characterized by a low fetal and placental vascular resistance. In the presence of intrauterine growth restriction (IUGR), there is an elevated pulsatility index in the fetal descending aorta and umbilical artery and reflecting increased umbilical, placental and utero-placental vascular resistance [5]. At the cardiac level, Doppler flow velocity waveforms have been previously recorded in the fetal heart outflow tracts in normally developed pregnancies [5$10]$ and those with fetal growth restriction [1,3,4,11-13].

The current management of FGR involves the use of Doppler at the peripheral arterial circulation (middle cerebral and umbilical arteries), 
at central venous vessels (Ductus venosus and inferior vena cava), and with cardiotocography [4]. In the fetus, the Doppler evaluation of the main pulmonary artery has been shown to be useful in the analysis of the impedance of such vascular systems and changes in those variables have been demonstrated to correlate with gestational age, fetal lung maturity and neonatal outcomes [8,14-20]. Adding central arterial Doppler (aortic and pulmonary artery waveforms) may improve management of the fetus with FGR, but studies are lacking on the prospective clinical evaluation of the ventricular outflow tracts Doppler in FGR fetuses.

In this study we choose to compare the Doppler waveform variables at the fetal right ventricle outflow tract, at main pulmonary artery (MPA) in normally grown and growth restricted fetuses. The objective of our study was two-fold:

1. To establish the distribution of peak systolic velocities (PSV) and pulsatility indices (PI) of the fetal cardiac right outflow tract (main pulmonary artery) in normally grown fetuses of singleton pregnancies.

2. To determine the degree of abnormality of MPA-PSV and MPAPI in growth restricted fetuses compromised with abnormal umbilical artery pulsatility indices (UMA-PI) and to compare these Doppler waveform variables between the two groups.

\section{Material and Methods}

\section{Study Design}

This prospective multicenter case-control study was conducted from April 2019 to March 2020 at three referral academic centers affiliated to Tehran university of medical science (Imam Khomeini complex, Dr Shariati hospital, Yas hospital). The study was approved by Tehran university ethics committee (ethics code: IR.TUMS. MEDICINE.1398.072) and all women gave their informed consents to participate [2].

\section{Setting}

60 healthy women with singleton pregnancies and normally grown fetuses (abdominal circumference between $10^{\text {th }}$ and $90^{\text {th }}$ percentile, and estimated fetal weight between $10^{\text {th }}$ and $90^{\text {th }}$ percentile) at 27 to 29 weeks gestation entered the study as the control group and compared with 60 pregnant women with intrauterine growth restricted fetuses included the study as the case group.

Growth restricted fetuses were defined by the following criteria:

1. Gestational age was defined by either the first trimester crown-rump length (CRL) ultrasound or by the last menstrual period confirmed by ultrasound examination before 20 weeks gestation.

2. Abdominal circumference (AC) less than $10^{\text {th }}$ percentile, or estimated fetal weight (EFW) less than $10^{\text {th }}$ percentile prior to 32 weeks gestation.

3. Early placental insufficiency as defined by umbilical artery pulsatility index (UMA-PI) elevation equal or more than $95^{\text {th }}$ percentile at the first time of examination.
4. To be eligible for longitudinal analysis, it was necessary for patients to have had at least three Doppler examinations prior to delivery.

5. Maternal age, gestational age, and maternal history of medical disorders was individually matched between two groups.

\section{Eligibility Criteria}

Mothers who consumed corticosteroids or any medication that could affect the fetal heart or lungs, such as antihypertensive drugs or corticosteroids were excluded. Fetuses with chromosomal abnormalities, structural anomalies, advanced fetal vascular disease (brain sparing, absent or reversed flow in umbilical artery, elevated ductus venosus pulsatility index, absent or reversed a-wave in ductus venosus), fetuses with any major structural heart defect or arrhythmias and non-singleton pregnancies were excluded.

\section{Study Procedure}

After recruitment, fetal biometry was assessed every two weeks and Doppler studies were obtained by a single operator. We categorized the fetuses into five gestational age periods; 26-29, 30-32, 33-34, 3537 , and 38-40 weeks. The study was performed using a Philips affinity $70 \mathrm{w}$ ultrasound machine equipped with a C9-2 convex transducer. All fetuses were in a quiet state without fetal breathing movements. The fetal MPA was visualized in the short-axis view. The pulsed Doppler sample gate was placed at the middle of the fetal MPA, between the pulmonary valves and the pulmonary artery bifurcation, and away from arterial walls. After enlarging the image, the sample gate was adjusted to $2-3 \mathrm{~mm}$ due to pulmonary artery diameter and the angle of insonation was maintained at less than 15 degrees. Doppler gain and scale were adjusted, and the high-pass filter was set at $100 \mathrm{~Hz}$ to record diastolic blood flow. Velocity range of blood flow was 100 $\mathrm{cm} / \mathrm{s}$ and the sweep speed was $200 \mathrm{~mm} / \mathrm{s}$. Doppler variables including MPA pulsatility index (MPA-PI) and MPA peak systolic velocity (MPA-PSV), were measured at least three times during each study, using manual-trace and measurements were averaged. The last MPA Doppler examination was done within 48 hours before delivery [3].

\section{Statistical Analysis}

Statistical analysis was performed using SPSS version 21.0 (SPSS, Inc, Chicago, IL). The data were expressed as number (\%) and mean (SD). Clinical and demographic characteristics between the cases and the controls were compared through Chi-square test for categorical variables and student $t$ test for continuous variables. Linear regression analysis was used to investigate the relationship between the individual fetal MPA Doppler waveform variables and gestational age. Moreover, logistic regression was used to investigate the effect of fetal MPA Doppler waveform on RDS in neonates. $\mathrm{P}<0.05$ was considered statistically significant.

\section{Results}

A comparison of the maternal demographic and clinical data between case and control group is shown in Table 1 and 2; Figures 1 and 2 . 
Table 1: Comparison of Baseline Demographic and Clinical Characteristics between Case and Control Groups.

\begin{tabular}{|l|c|c|c|}
\hline \multirow{2}{*}{ Variable } & Case group & Control group & \multirow{2}{*}{ P. value } \\
\cline { 2 - 3 } & $\mathbf{N}$ (\% or SD) & N (\% or SD) & \\
\hline Cesarean delivery & $54(90)$ & $37(61.67)$ & $<0.001$ \\
\hline Un-usual Apgar & $42(70)$ & $10(16.67)$ & $<0.001$ \\
\hline NICU admission & $49(81.67)$ & $14(23.33)$ & $<0.001$ \\
\hline RDS & $49(81.67)$ & $14(23.33)$ & $<0.001$ \\
\hline ASA consumption & $26(43.33)$ & $15(25.00)$ & 0.034 \\
\hline Allergy & $9(15.00)$ & $8(13.33)$ & 0.79 \\
\hline Smoking & $5(8.33)$ & $5(8.33)$ & 1 \\
\hline Infertility & $9(15.00)$ & $5(8.33)$ & 0.26 \\
\hline Parity 0 & $29(48.33)$ & $31(51.67)$ & 0.28 \\
\hline 1 & $22(38.33)$ & $26(43.33)$ & \\
\hline 2 & $8(13.33)$ & $3(5.00)$ & 0.94 \\
\hline Age (year) & $32.1(5.87)$ & $32.02(5.71)$ & 0.94 \\
\hline
\end{tabular}

The percentage of cesarean delivery ( $90 \%$ vs. $61.67 \%$ ) was significantly higher in case group. There wasn't significant difference between two groups in regard of allergy, smoking, infertility and parity. MPA Doppler variables at each 2-week gestational age intervals in both case and control groups are presented in Table 2 and Figures 1 and 2.

Table 2: Changes in MPA-PSV and MPA-PI with Gestational Age in Case and Control Groups.

\begin{tabular}{|l|c|c|c|c|c|c|}
\hline $\begin{array}{l}\text { Gestational } \\
\text { Age }\end{array}$ & $\begin{array}{c}\text { MPA-PSV in } \\
\text { Case }\end{array}$ & $\begin{array}{c}\text { MPA-PSV in } \\
\text { Control }\end{array}$ & P.Value & MPA-PI in & MPA-PI in & P.Value \\
\hline (weeks) & Group & Group & & Case Group & $\begin{array}{c}\text { Control } \\
\text { Group }\end{array}$ & \\
\hline $26-29$ & $54.26 \pm 11.05$ & $42.81 \pm 19.08$ & $<0.001$ & $2.81 \pm 0.33$ & $2.58 \pm 0.32$ & $<0.001$ \\
\hline $30-32$ & $37.70 \pm 11.52$ & $55.76 \pm 19.15$ & $<0.001$ & $3.67 \pm 0.36$ & $2.26 \pm 0.26$ & $<0.001$ \\
\hline $33-34$ & $33.81 \pm 9.99$ & $68.53 \pm 21.45$ & $<0.001$ & $3.87 \pm 0.28$ & $2.14 \pm 0.29$ & $<0.001$ \\
\hline $35-37$ & $28.49 \pm 7.18$ & $69.25 \pm 12.98$ & $<0.001$ & $3.97 \pm 0.23$ & $2.06 \pm 0.20$ & $<0.001$ \\
\hline $38-40$ & $39.23 \pm 10.89$ & $69.85 \pm 18.51$ & 0.007 & $3.77 \pm 0.38$ & $2.05 \pm 0.16$ & $<0.001$ \\
\hline Overall & $41.59 \pm 14.31$ & $56.20 \pm 21.60$ & $<0.001$ & $3.49 \pm 0.63$ & $2.31 \pm 0.34$ & $<0.001$ \\
\hline
\end{tabular}

In all five time intervals the mean of MPA-PI was significantly higher in cases than controls (P\&lt;0.001). The mean of MPA-PI in cases was increasing with gestational age, while in the control group it was decreasing. Also, in all time intervals, the mean of MPA-PSV was significantly higher in the control group (P\&lt;0.001). The mean of MPA-PSV in cases was decreasing by advancing the gestational age, while in the control group it was increasing.

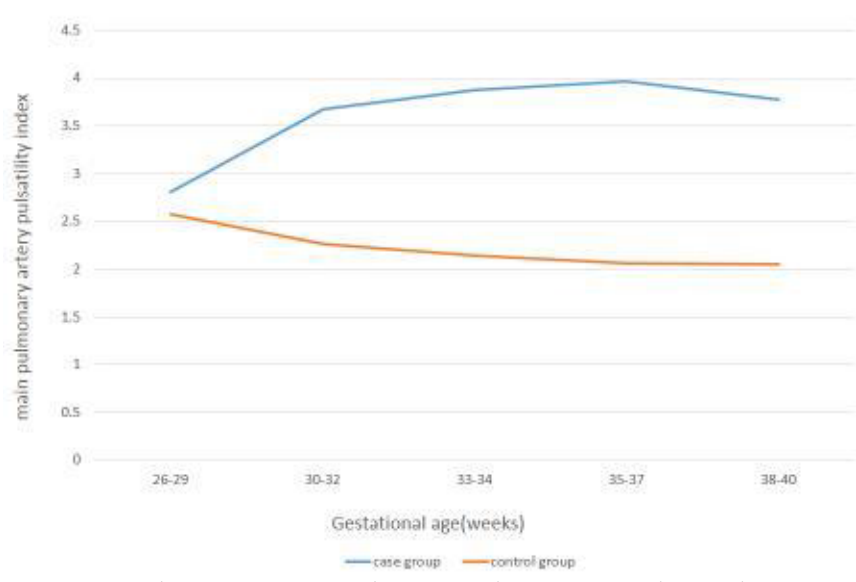

Figure 1: Changes in MPA-PI with Gestational Age in Case and Control groups.

Table 3: Regression Equations for MPA-PI and MPA-PSV with Gestational Age.

\begin{tabular}{|l|c|c|c|c|}
\hline Doppler parameters & Regression Equations & R2 & F & P.Value \\
\hline MPA-PI & $\mathrm{Y}=-1.35+0.16 \mathrm{x}$ & 0.31 & 80.83 & $<0.001$ \\
\hline MPA-PSV & $\mathrm{Y}=136.4-3.08 \mathrm{x}$ & 0.23 & 53.09 & $<0.001$ \\
\hline
\end{tabular}

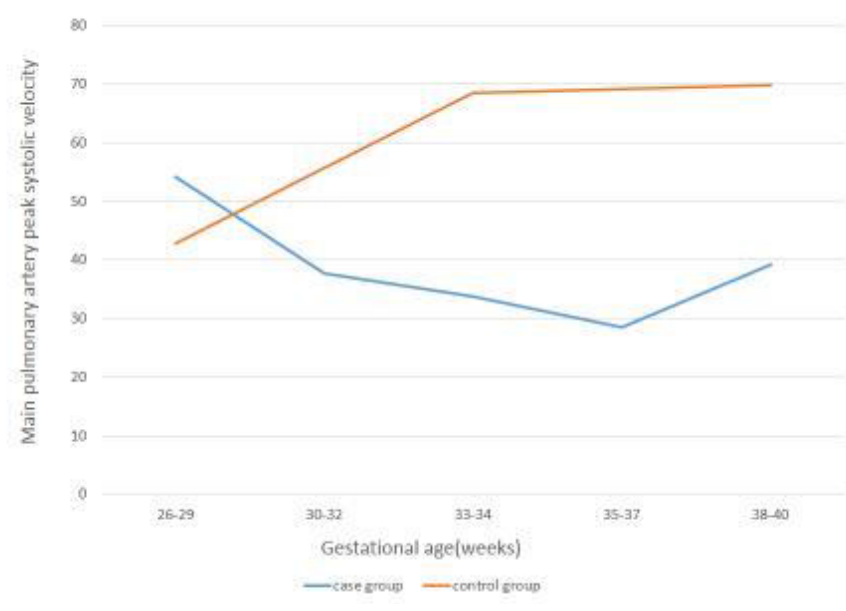

Figure 2: Changes in MPA-PSV with Gestational Age in Case and Control groups.

In the case group, as shown in Table 3, per one-week increase in gestational age, MPA-PI increased as $16 \%(\beta=0.16$, p\&lt;0.001), while MPA-PSV significantly decreased, significantly $(\beta=-3.08$, p\&lt;0.001).

\section{Discussion}

This study aimed to determine the main pulmonary artery Doppler waveforms changes in normally grown and growth restricted fetuses during gestation, and to compare the MPA Doppler indices between two groups. In the present study, the MPA flow velocity wave forms, were successfully recorded in all fetuses. In normally developed fetuses (the control group), with increasing gestational age, the MPA-peak systolic velocity increased, and the MPA-pulsatility index decreased significantly. These findings are compatible with prior publications by Chaoui et al. [10], Guan et al. [8], and Herren et al. [6].

Fetal oxygen exchange occurs almost exclusively in the placenta and not in the lungs. For this reason, the pulmonary circulation in the fetus is maintained in a state of high resistance, high pressure, and low flow. Doppler ultrasonography provides a simple, noninvasive, and reproducible technique of directly evaluating the status of the fetal pulmonary circulation [8]. As pregnancy progresses, the vascular beds of the fetal lungs expand, leading to a progressive decrease in pulmonary arterial vascular resistance and a slow increase in pulmonary blood flow. These changes might explain the elevation in pulmonary artery peak systolic velocity and the reduction in the pulsatiliy index as well [8].

Herren et al. determined reference ranges for Doppler parameters (PI and PSV) of fetal pulmonary artery segments (proximal, middle and distal) in 150 healthy singleton pregnancies from 19 to 39 weeks of gestation [6]. The mean PI and PSV values (mean \pm SD) in the middle segment of MPA were $2.52 \pm 0.96$ and $24.39 \pm 11.86$, respectively. We measured the MPA-PI and MPA-PSV in the middle segment of main pulmonary artery.

Guan et al. defined reference ranges for fetal main pulmonary artery (MPA) Doppler waveform parameters in 288 healthy fetuses throughout gestation [8]. They used MPA Doppler indices to 
predict the subsequent development of neonatal respiratory distress syndrome (RDS) in a prospective cohort of 52 pregnant women with impending preterm birth before 37 weeks gestation. The authors concluded that the acceleration time (AT), acceleration time/ ejection time ratio (AT/ET), peak systolic velocity (PSV), and mean velocity (MV) were significantly lower in the RDS group than in the non-RDS group. All these variables showed no significant differences between the two groups. They mentioned that AT and AT/ET ratios of the fetal MPA Doppler waveform less than or equal to the $5^{\text {th }}$ percentile for gestational age may provide a reliable noninvasive test to identify fetuses at risk of developing neonatal RDS.

Our study has focused on a special group of growth restricted fetuses (estimated fetal weight below $10^{\text {th }}$ centile) that were diagnosed at 26-27 weeks gestation and pulsatility index above $95^{\text {th }}$ centile showed in their umbilical artery Doppler study. So far, there hasn't been any similar prior case-control studies to be acknowledged. In our study, there was significant difference in the MPA Doppler variables between the two groups. In all time intervals, the mean MPA-PI was significantly higher in cases than controls $(\mathrm{p}<0.001)$. Also, from 30 to 38 weeks gestation, the mean MPA-PSV was significantly lower in the case group $(\mathrm{p}<0.05)$. The mean MPA-PI in growth restricted fetuses (the case group), increased by the increase of gestational age, while it reduced in the control group. The mean MPA-PSV in the case group, decreased by the increase of gestational age, while it increased in the control group.

We followed all cases, evaluating the MPA Doppler waveforms every 2 weeks of gestation and during 48 hours before delivery, and the longitudinal assessment of MPA Doppler measurements within the same gestational ages was done in the control group. We noticed that the significant differences in the MPA Doppler indices existed between normally grown and IUGR fetuses with the umbilical artery Doppler pulsatility index $>95^{\text {th }}$ centile. An interesting finding in the case group was the concurrent occurrence of centralization and Doppler impairment in the main pulmonary artery. Centralization, so called Brain sparing effect, is defined as middle cerebral artery pulsatility index (MCA-PI) less than $5^{\text {th }}$ centile and cerebro-placental ratio $<1$. In \%73.3 (n: 44/60) of IUGR cases, we had detections of simultaneous $\mathrm{MCA}-\mathrm{PI}<5^{\text {th }}$ centile and MPA-PI $>95^{\text {th }}$ centile.

Groenenberg and colleagues evaluated the fetal cardiac outflow tracts (ascending aorta and pulmonary artery) peak systolic velocities in 46 normal pregnancies and 21 IUGR cases. In normal fetuses, the mean PSV in the pulmonary artery increased from $39.0 \mathrm{~cm} / \mathrm{s}$ at 19 weeks gestation to $63.7 \mathrm{~cm} / \mathrm{s}$ at 33 weeks. In IUGR fetuses the PSV in the pulmonary artery was decreased $\left(<5^{\text {th }}\right.$ percentile) in $95 \%$ of cases, and no relationship was established between PSV in pulmonary artery and the presence or absence of end-diastolic flow velocities in the umbilical artery [4].

Verburg et al. mentioned in their prospective cohort study that decreased fetal growth is associated with adaptive fetal cardiovascular changes [13]. Cardiac remodeling and cardiac output changes are consistent with a gradual increase in after load and compromised in arterial compliance in conditions of diminished fetal growth. Furthermore, fetal hemodynamic patterns have already begun to change in the presence of reduced fetal growth while the fetus is still within the normal estimated fetal weight range. Evidence of reduced myocardial contractility in the presence of severe IUGR has also been reported by Rizzo et al. [2] and Makikallio et al. [1].

We concluded that there were noticeable changes in the right ventricular outflow tract of the fetal heart in the growth restricted fetuses. In the case group, per one week increase in gestational age, the MPA-PI increased as $16 \%(\mathrm{p}<0.001)$, while the MPA-PSV decreases significantly $(\mathrm{p}<0.001)$.

Moety and colleagues measured MPA-PSV, PI and AT/ET in 643 healthy fetuses, aged 34 to $38+6$ weeks, without postnatal respiratory distress syndrome [14]. The strongest correlation was found with AT/ ET (cutoff value: 0.305 ). They provided $76.4 \%$ sensitivity and $91.6 \%$ specificity for prediction [7] of postnatal RDS. The MPA-PI was significantly higher, whereas MPA-PSV was significantly lower in fetuses that developed RDS.

Our study emphasizes the role of placental insufficiency in the course of fetal growth restriction. Placenta, although is not placed directly on the course of pulmonary artery flow, it can indirectly affect the PA flow on its way to the descending aorta $[21,22]$. Pulmonary artery flow faces three different downstream resistances; the highresistance-non-aerated fetal lungs, the lower resistance-aortic vascular bed and placental vascular bed with the lowest resistance in normal pregnancy [9]. The MPA-PSV reflects right ventricular systolic function and in our study it reduced in growth restricted fetuses. The MPA-PI influences by systolic and diastolic pulmonary artery pressure and central venous pressure. In the presence of IUGR, there is an elevated pulsatility index in the fetal descending aorta and umbilical artery, reflecting increased placental vascular resistance [5].

Our study showed that not only the umbilical and middle cerebral arteries were affected by the elevated placental impedance in FGR fetuses, but also the main pulmonary artery was influenced by placental vascular insufficiency. We compared fetal pulmonary artery PI and PSV between normally grown and growth restricted fetuses almost at the same gestational ages. It permits better comprehension of fetal circulation and cardiac hemodynamics in diminished fetal growth. We chose to assess two Doppler variables (PI and PSV) and the other variables (AT, ET) didn't evaluate in our study. Subsequent large prospective studies are needed to better investigate the occurrence of adverse Doppler measurements in this part of the fetal circulation.

\section{Aknowledgement}

The authors would like to express their deepest gratitude to the perinatology department of Tehran University and the head professors for their continuous support.

\section{Conflict of Interest}

None.

\section{References}

1. Makikallio K, Vuolteenaho O, Jouppila P, Juha Räsänen (2002) Ultra sonographic and biochemical markers of human fetal cardiac dysfunction in placental insufficiency. Circulation 105: 2058-2063. [crossref] 
2. Rizzo G, Capponi A, Rinaldo D, Arduini D, Romanini C (1995) Ventricular ejection force in growth restricted fetuses. Ultrasound Obstet Gynecol 5: 247-255. [crossref]

3. Figueras F, Puerto B, Martinex JM, Vicenç Cararach, et al. (2003) Cardiac function monitoring of fetuses with growth restriction. Eur J Obstet Gynecol Reprod Biol 110: 159-163. [crossref]

4. Groenenberg IAL, Stijnen T, Wladimiroff JW (1990) Flow velocity waveforms in the fetal cardiac outflow tract as a measure of fetal well-being in intrauterine growth retardation. Pediatr Res 27: 379-382. [crossref]

5. Huhta JC, Moise KJ, Fisher DJ, Sharif DS, Wasserstrum N, et al. (1987) Detection and quantitation of constriction of the fetal ductus arteriosus by Doppler echocardiography. Circulation 75: 406-412. [crossref]

6. Herren H, Junior EA, Wellington P, Ricardo CC, Alessandra CM et al. (2016) Reference ranges of Doppler parameters of fetal pulmonary artery segments between 19 and 39 weeks gestation. J Matern Fetal Neonatal Med 29: 85-90. [crossref]

7. Sosa Olavarria A, Zurita Peralta J, Schenone CV, Scherone MH, Prieto F (2019) Doppler evaluation of the fetal pulmonary artery pressure. J Perinatol Med 47: 218221. [crossref]

8. Guan Y, Li S, Luo G, Wang C, Norwitz ER, et al. (2015) The role of Doppler waveforms in the fetal main pulmonary artery in the prediction of neonatal respiratory distress syndrome. J clin Ultrasound 43: 375-383. [crossref]

9. Malekan rad E, Aghaei ME, Majnoon M, Nikoofar M, Kocharian A, et al. (2018) Comparison of reference values and $\mathrm{Z}$ scores of pulse-Doppler waveforms of fetal pulmonary artery and aorta. Iran J Pediatr 28.

10. Chaoui R, Taddei F, Rizzo G, C Bast, F Lenz, et al. (1998) Doppler echocardiography of the main stems of the pulmonary arteries in the normal human fetus. Ultrasound Obstet Gynecol 11: 173-179. [crossref]

11. Baschat AA, Hecher K (2004) Fetal growth restriction due to placental disease. Semin Perinatol 28: 67-80. [crossref]
12. Boito S, Struijk PC, Ursem NT, Stijnen T, Wladimiroff JW (2002) Umbilical venous volume flow in the normally developing and growth restricted human fetus. Ultrasound Obstet Gynecol 19: 344-349. [crossref]

13. Verburg BO, Jaddoe V, Wladimiroff JW, Hoffman A, Jacqueline C M et al. (2008) Fetal hemodynamic adaptive changes related to intrauterine growth the generation $\mathrm{R}$ study. Circulation 117: 649-659. [crossref]

14. Moety GA, Gaafar HM, El Rifai NM (2015) Can fetal pulmonary artery Doppler indices predict neonatal respiratory distress syndrome? J Perinatol 35: 1015-1019.

15. Buke B, Destegul E, Akkaya H, Simsek D, Kazandi M (2019) Prediction of neonatal respiratory distress syndrome via pulmonary artery Doppler examination. J Matern Fetal Neonat Med 32: 1640-1645. [crossref]

16. Kim SM, Park JS, Norwitz ER, Hwang EJ, et al. (2013) Acceleration time-to-ejection time ratio in fetal pulmonary artery predicts the development of neonatal respiratory distress syndrome: a prospective cohort study. Am J Perinatol 30: 805-812. [crossref]

17. Azpurua H, Norwitz ER, Campbell KH, Funai EF, Pettker CM, et al. (2010) acceleration/ejection time ratio in the fetal pulmonary artery predicts fetal lung maturity. Am J Obstet Gynecol 203. [crossref]

18. Schenone MH, Samson JE, Jenkins L, Suhag A, Mari G (2014) Predicting fetal lung maturity using the fetal pulmonary artery Doppler wave acceleration/ejection time ratio. Fetal Diagn Ther 36: 208-214. [crossref]

19. Zare Mehrjardi M (2019) Fetal pulmonary artery Doppler examination as a noninvasive test for assessing prenatal lung maturity. Iran Cong Radiol 35: 89-89.

20. Aboulghar M, Khalifa Y, Hamed ST, Tomerak R, Kamal E (2019) Prenatal prediction of lung maturity using pulmonary artery Doppler and 3D ultrasound. Ultrasound Obstet Gynecol 54: 107-108.

21. Poston L (1997) The control of blood flow to the placenta. Exp Physiol 82: 377-387. [crossref]

22. Boura ALA, Leitch IM, Read MA, Walters WAW (1998) The control of fetal vascular resistance in the human placenta. Placenta 19: 299-313. 